\title{
EFFECTIVENESS OF OLIVE OIL ADMINISTRATION THROUGH NG TUBE TO IMPROVE WEIGHT AMONG LOW BIRTH WEIGHT BABIES
}

\author{
Mrs. Arunakumari Gade*| Dr. Bimla Rani** \\ * Research Scholar, Himalayan University, Itanagar, Arunachal Pradesh, India. \\ **Research Supervisor, Himalayan University, Itanagar in Arunachal Pradesh, India. \\ DOI: http://doi.org/10.47211/trr.2021.v07i02.007
}

\begin{abstract}
Background and objectives: An Experimental Study was carried out on "Effectiveness on administration of olive oil through NG tube to improve weight among low birth weight babies admitted in NICU at SVS Hospital, Yenugonda, Mahabubnagar, Telangana. Objectives of the study is to assess the weight of low birth weight babies before and after administration of olive oil through NG tube. To compare the mean difference of weight among low birth weight babies before and after administration of olive oil through NG tube. To determine the association between effect of administration of olive oil through NG tube among low birth weight babies with their selected demographic variables.

Materials and Methodology: The research design selected for the study was pre-experimental design. One group pre test and post test design with sampling. Only one group was observed before and after the independent variable was introduced. In this design the total sample was taken as one group and pre-test was administered. After the pre-test, irrespective of the pre-test results, the Investigator administered olive oil through NG tube. The effectiveness of independent variable on dependent variable was tested with the help of posttest. In the present study the sample were 40 babies were with low birth weight. The babies were selected by using the sample size consists of 40 babies I those who had been diagnosed with low birth weight. Among those, 20 participants were selected for experimental group and 20 for control group.

Results: The collected data was analyzed by using both descriptive and inferential statistics such as frequency and percentage distribution, Mean, standard deviation, paired' test and chi square test at 0.01 level of significance with $29 \mathrm{df}$. The mean score on level of weight gain in experimental group was 1415.25 in post test and 1104.85 in control group post test. The estimated paired ' $t$ ' value was 3.88 which is significant at $p 0.001$. It indicates that administration of olive oil through NG tube was effective in improving weight among low birth weight babies. Hence research hypothesis $H 1$ was accepted.

Conclusion: The study has showed that there was an overall improvement in the weight among low birth weight babies after administration of olive oil through NG tube to improve weight among low birth weight babies.
\end{abstract}

Keywords: olive oil, emulsification, fortifiers, low birth weight, NG tube, NICU

\section{ABOUT AUTHORS:}

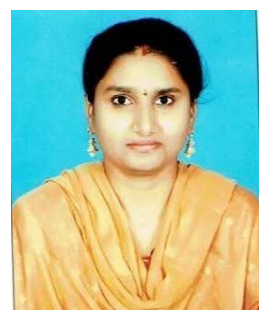

Author Mrs. Arunakumari Gade is a Research Scholar at Himalayan University, Itanagar in Arunachal Pradesh, India.

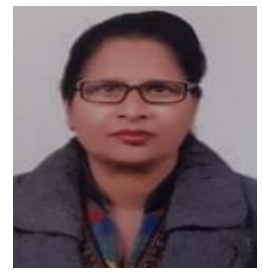

Author Dr. Bimla Rani is a Research Supervisor at Himalayan University in Itanagar, Arunachal Pradesh, India. She has presented papers in various conferences and also has many publications to her name. 


\section{INTRODUCTION}

The miracle of life begins at conception and continues, throughout the life span. The manifestations of this miracle is encountered during new born and infancy Neonates period is the crucial period for the infant who is facing many of the physiological adjustment for extra uterine existence.

Very low birth weight and preterm babies are functionally immature and physical care is needed for the survival is relevant especially in the topics to segregate the babies requiring special care out of the large number of newborn of low birth weight. Optimal nutrition is the critical in the management of the ever-increasing number of surviving small premature infants. Although the most appropriate goal of nutrition of the low birth weight infant is not definitively known .Delivering adequate amounts of nutrients to premature infants at all times is challenging because the infants immature gastro intestinal tract is initially unable to accept feedings, necessitating the use of parenteral nutrition. Current good practices regarding parenteral nutrition are guidelines for the introduction and advancement of enteral feedings. Because of its trophic effects on the Gl tract and its anti-infectious effects ,human milk is strongly preferred as the early feeding of choice for premature infants.

The basal metabolic rate of low-birth-weight infants is lower than that of full term infants during the first week of life, but reaches and exceeds that of the full term infant by the second week. Daily caloric requirement reach 50 to $100 \mathrm{kcal} / \mathrm{kg}$ by the end of the first week of life and usually increase to 110 to $150 \mathrm{kcal} / \mathrm{kg}$ in subsequent active growth.

Since similar human milk fortifiers are expensive and not easily accessible in our country's market, and based on the world wide medical experiences, we came to a decision to substitute lipids.Some of the lipids are fish oil ,soy oil, palm oil ,coconut oil ,margarine lipids among these olive oil is the most effective and the best suitable alternative lipid fortifier, olive oil is proved to be the low birth weight enhancing alternative without any chemicals in it , which also nourishes the infants by the wholesome as a milk fortifier in order to provide additionally needed calories intended for neonatal growth

\section{NEED FOR THE STUDY}

According to WHO the Global incidence as per 2017, India has been recorded the highest among rate of incidence of low birth weight babies of about 8.3 millions ,Africa 4.1 million, South Asia 2.7 million, East Asia 1.7 million, North Africa 1.4 million, Latin America 1 million incidences and least rate is recorded in the developing countries of about 200,000 thousand rate of incidence.

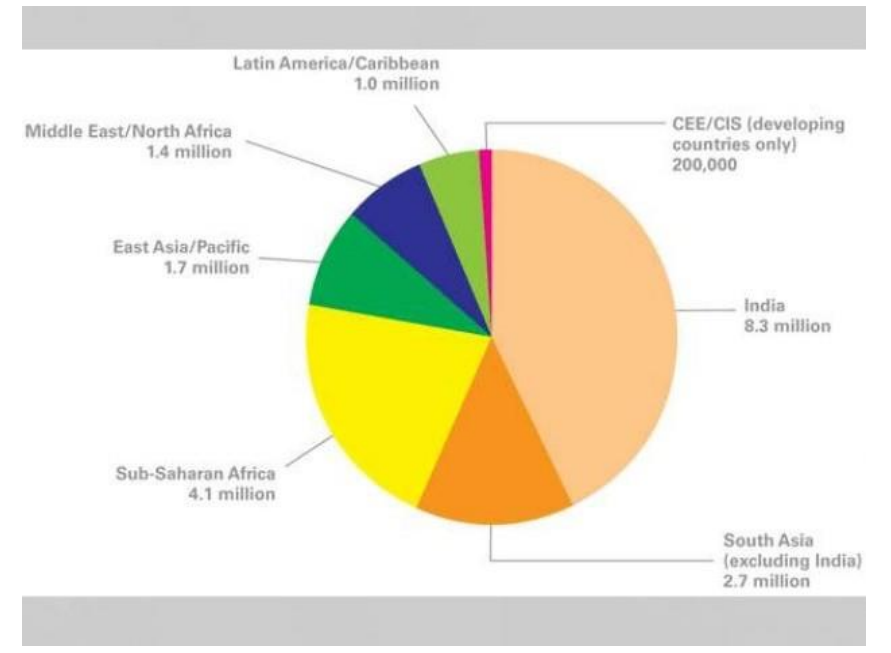

Figure .1: Global wide incidence rate of low birth weight babies

As per the best known observational source of study and analysis of low birth weight, rate of incidence in India eleven states with highest number of low birth weight babies. The state wise recorded low birth rate of incidences are as follows with highest rate is recorded low birth rate of incidences are as follows Rajasthan 431,282; Gujrat 108,825; Maharashtra 282,990 ;Karnataka104,886;Tamilnadu 106,045 ;west Bengal 213,146; Madhyapradesh249,289; Bihar 129,668; Andhra Pradesh 85,975 with highest rate is recorded in uttar pradesh which is 824,533 and Telangana stands second in the country 536,286 this was announced by the union minister of health and family welfare. 
As per 2017 incidence of low birth weight babies born in Telangana state were 62.7\% year in Hyderabad, 89.8\% year in Khammam,, 52.2\% year ,Adilabad, 71\%year, Medak, 63.6\% year ,Nalgonda, 80.9\% year Mahabubnagar, $58.6 \%$ year in karimnagar, $48.2 \%$ Nizambad, 69.6\% in Rangareddy, 59.1\% in Warangal.

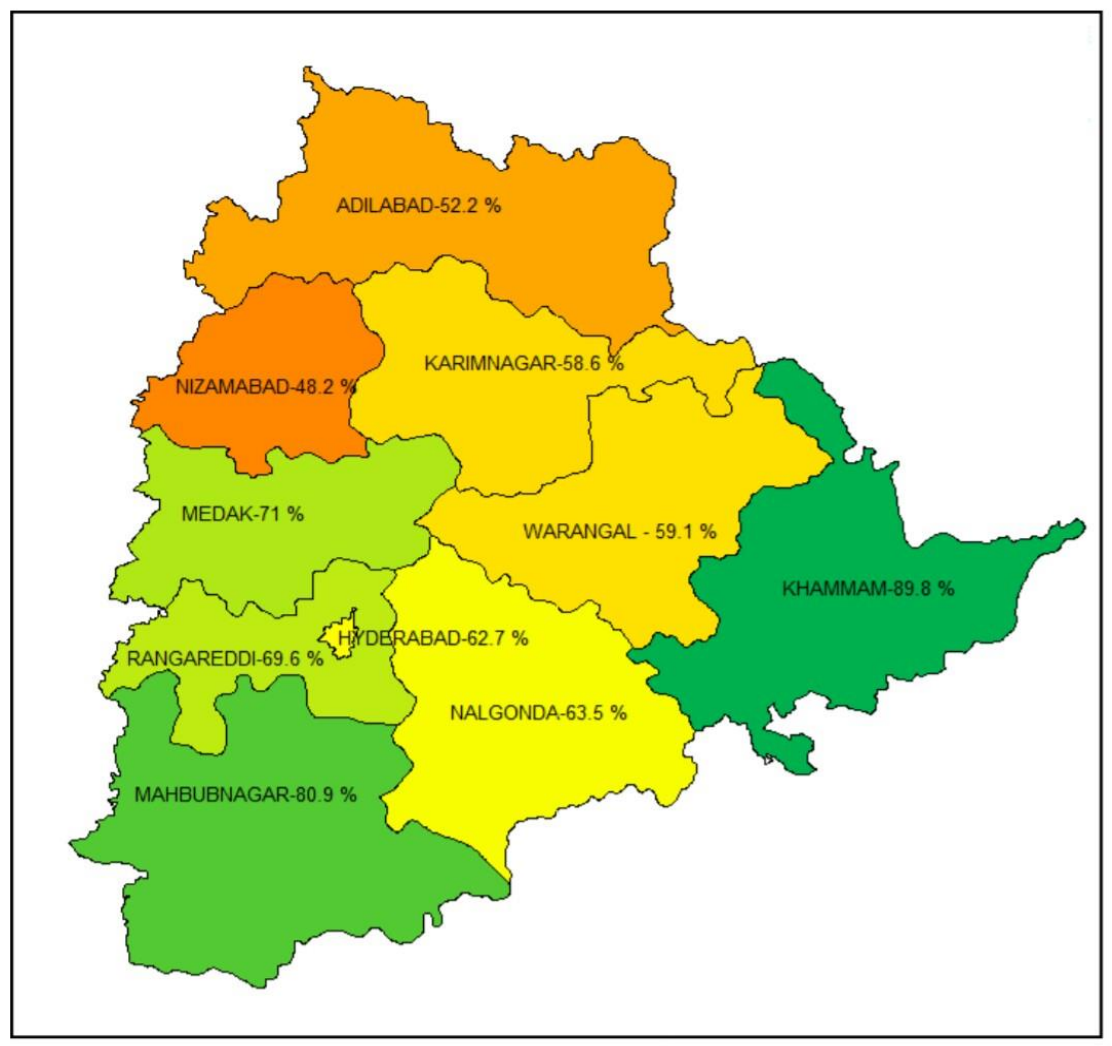

Figure .2: Telangana state incidence rate of low birth weight babies

In S.V.S hospital 2018 census in neonatal intensive care unit admission of pre term and low birth weight babies were 20-30 per month.

HYPOTHESIS:

H1: There will be significant difference between before and after administration of olive oil through NG tube among low birth weight babies.

H2: There will be significant association between pre and post test level of administration of olive oil through NG tube among low birth weight babies.

\section{METHODOLOGY:}

The research design selected for the study was pre-experimental design. More specifically, one group pre-test, post test design was used in which only one group was observed before and after the independent variable was introduced. In this design the total sample was taken as one group and pre-test was administered. After the pretest, irrespective of the pre-test results, the Investigator administered olive oil through NG tube. The effectiveness of independent variable on dependent variable was tested with the help of posttest. In the present study the sample were 40 babies were with low birth weight admitted in NICU at SVS Hospital, Yenugonda, Mahabubnagar, Telangana. The babies were selected by using the sample size consists of 40 babies I those who had been diagnosed with low birth weight. Among those, 20 participants were selected for experimental group and 20 for control group.

A pilot study was conducted from $15 / 05 / 20$ to 25/05/20 in NICU, SVS Hospital, Yenugonda, Mahabubnagar, Telangana. After obtaining formal permission from Head Of The Department, Neonatology, SVS Hospital, to assess the feasibility and reliability of the tool. The obtained value of Karl Pearson correlation of coefficient was $r=0.99$, which infers the tool as reliable. The main study was conducted in NICU at SVS Hospital, Yenugonda, Mahabubnagar, Telangana from $02 / 06 / 20$ to 30/06/20. The collected data was analysed by using both descriptive and inferential statistics such as frequency and percentage distribution, Mean, standard deviation, paired' test and chi square test at 0.01 level of significance with $29 \mathrm{df}$. 


\section{RESULTS}

Findings of the study were discussed.

The demographic variable in experimental group $6(30 \%)$ of them belonged to the age group of $<18$ years, $3(15 \%)$ belongs to $18-20$ years, $4(20 \%)$ belongs to $20-30$ years, $7(35 \%)$ belongs to $>30$ years. Regarding religion $4(20 \%)$ are Christians, $9(45 \%)$ are Hindus, 3(15\%) are Muslims, 4(20\%) are others. Regarding mothers habits during pregnancy $5(25 \%)$ were smoking, $7(35 \%)$ were alcoholism, 5(25\%) were tobacco chewing, 3(15\%) are none. Regarding education $5(25 \%)$ are post graduates, $7(35 \%)$ are graduates, $7(35 \%)$ secondary education, $1(5 \%)$ is illiterate. Regarding marriage $7(35 \%)$ are consanguineously married, $13(65 \%)$ are not consanguineously married. Regarding anaemic status of mother $5(25 \%)$ normal, $7(35 \%)$ mild, $7(35 \%)$ moderate, $1(5 \%)$ severe. Regarding radiation exposure $13(65 \%)$ were exposed $7(35 \%)$ II were not exposed. Regarding weight gain during pregnancy $9(45 \%)$ are $10 \mathrm{~kg}$. Regarding type of delivery $4(20 \%)$ are FTNVD, 5(25\%) are assisted delivery, 10(50\%) are undergone csection, $1(5 \%)$ was preterm delivery. Regarding source of information $2(10 \%)$ from internet, $3(15 \%)$ from web series, $5(25 \%)$ from social media, $5(25 \%)$ from health workers, $5(25 \%)$ from none. Regarding awareness on weight gain supplements $8(40 \%)$ regarding olive oil, $7(35 \%)$ regarding lipid emulsions, $5(25 \%)$ regarding formula feeding. Regarding gestational age of the mother $3(15 \%)$ are $37-35$ weeks, $7(35 \%)$ are $35-33$ weeks, $6(30 \%)$ are $33-30$ weeks, $4(20 \%)$ are 30 weeks. Regarding medical problems during antenatal period $7(35 \%)$ infection, 10(50\%) having placental factors, $3(15 \%)$ none. Regarding history of preterm delivery $14(70 \%)$ were preterm delivered, $6(30 \%)$ were not delivered. Regarding age of the infant $11(55 \%)$ are $0-7$ days, $3(15 \%)$ are $8-14$ days, $5(25 \%)$ are 15 21 days, $1(5 \%)$ is $21-28$ days. Regarding gender $12(60 \%)$ are males, $8(40 \%)$ are females. Regarding birth weight of the infant $8(40 \%)$ are $<18$ years, $4(20 \%)$ belongs to $18-20$ years, $3(15 \%)$ belongs to $20-30$ years, $8(40 \%)$ belongs to $>30$ years. Regarding religion $4(20 \%)$ are Christians, $9(45 \%)$ are Hindus, 3(15\%) are Muslims, 4(20\%) are others. Regarding mothers habits during pregnancy $5(25 \%)$ were smoking, $7(35 \%)$ were alcoholism, 5(25\%) were tobacco chewing, $3(15 \%)$ are none. Regarding education $5(25 \%)$ are post graduates, $6(30 \%)$ are graduates, $8(40 \%)$ secondary education, $1(5 \%)$ is illiterate. Regarding marriage $7(35 \%)$ are consanguineously married, $13(65 \%)$ are not consanguineously married. Regarding anaemic status of mother $5(25 \%)$ normal, $7(35 \%)$ mild, $8(40 \%)$ moderate, $0(0 \%)$ severe. Regarding radiation exposure $13(65 \%)$ were exposed $7(35 \%)$ were not exposed. Regarding weight gain during pregnancy $9(45 \%)$ are $10 \mathrm{~kg}$. Regarding type of delivery $6(30 \%)$ are FTNVD, $4(20 \%)$ are assisted delivery, $5(25 \%)$ are undergone

c-section, $5(25 \%)$ was preterm delivery. Regarding source of information $2(10 \%)$ from internet, $5(25 \%)$ from web series, $5(25 \%)$ from social media, $5(25 \%)$ from health workers, $3(15 \%)$ from none. Regarding awareness on weight gain supplements $8(40 \%)$ regarding olive oil, $7(35 \%)$ regarding lipid emulsions, $5(25 \%)$ regarding formula feeding. Regarding gestational age of the mother $2(10 \%)$ are $37-35$ weeks, $6(30 \%)$ are $35-33$ weeks, $6(30 \%)$ are $33-30$ weeks, $3(60 \%)$ are 30 weeks. Regarding medical problems during antenatal period $7(35 \%)$ infection, $2(10 \%)$ having placental factors, $7(35 \%)$ multiple IV gestations, $4(20 \%)$ none. Regarding history of preterm delivery $10(50 \%)$ were preterm delivered, $10(20 \%)$ were not delivered. Regarding high risk problems $0(0 \%)$ are preeclampsia, 1(5\%) placenta preavia, 9(45\%) PPH, 10(50\%) none. Regarding age of the infant 3(15\%) are 0-7 days, $5(25 \%)$ are $8-14$ days, $7(35 \%)$ are $15-21$ days, $5(25 \%)$ is $21-28$ days. Regarding gender $12(60 \%)$ are males, $8(40 \%)$ are females. Regarding birth weight of the infant $8(40 \%)$ are $<1000 \mathrm{grms} 10(50 \%)$ are $1000-1500 \mathrm{gm}, 2(10 \%)$ are 2000-2500gm. Regarding immediate cry 7(35\%) were immediately cried, 13(65\%) were absence of cry. Regarding Apgar score $8(40 \%)$ are $3-5,2(20 \%)$ are $5-7,0(0 \%)$ are $7-10,7(35 \%)$ are $<6$. Regarding presence of reflexes $7(35 \%)$ are $6-10,6(30 \%)$ are $10-12,0(0 \%) 12-14$. Regarding birth order $10(50 \%)$ are 1 st child, $8(40 \%)$ are $2^{\text {nd }}$ child, $2(10 \%)$ are 3 rd child. Regarding medical problems of child $7(35 \%)$ are metabolic disorder, $8(40 \%)$ are birth asphyxia, $0(0 \%)$ are me conium aspiration 5(25\%) are congenital anomalies. Regarding type of feeding $0(0 \%)$ are direct breast feeding, 2(10\%) are expressed breast feeding, 4(20\%) formula feeding, 14(70\%) are NG tube feeding $0(0 \%)$ spoon feeding. Regarding kangaroo mother care $14(70 \%)$ are every 2 nd hourly, $6(30 \%)$ every 4 th hourly, $0(0 \%)$ are 6 th hourly. Regarding time of initiation of feed after birth 5(25\%) 1-2 hours, 7(35\%) 2-4 hours , 6(30\%) 4-6 hours, 2 $(10 \%)$ after 6 hours. Regarding total number of feeds per day. $8(40 \%)$ every 2 nd hourly , $8(40 \%)$ every 4 th hourly, $4(20 \%)$ every 6th hourly.

The demographic variable in control group $5(25 \%)$ of them belonged to the age group of $<18$ years, $4(20 \%)$ belongs to $18-20$ years, $3(15 \%)$ belongs to $20-30$ years, $8(40 \%)$ belongs to $>30$ years. Regarding religion $4(20 \%)$ are Christians, 9 (45\%) are Hindus, 3(15\%) are Muslims, 4(20\%) are others. Regarding mothers habits during pregnancy $5(25 \%)$ were smoking, 7(35\%) were alcoholism, 5(25\%) were tobacco chewing, 3(15\%) are none. Regarding education $5(25 \%)$ are post graduates, $6(30 \%)$ are graduates, $8(40 \%)$ secondary education, $1(5 \%)$ is illiterate. 
Regarding marriage $7(35 \%)$ are consanguineously married, $13(65 \%)$ are not consanguineously married. Regarding anaemic status of mother $5(25 \%)$ normal, $7(35 \%)$ mild, $8(40 \%)$ moderate, $0(0 \%)$ severe. Regarding radiation exposure $13(65 \%)$ were exposed $7(35 \%)$ were not exposed. Regarding weight gain during pregnancy $9(45 \%)$ are 10 kg. Regarding type of delivery 6(30\%) are FTNVD, 4(20\%) are assisted delivery, 5(25\%) are undergone c-section, $5(25 \%)$ was preterm delivery. Regarding source of information 2(10\%) from internet, 5(25\%) from web series, $5(25 \%)$ from social media, $5(25 \%)$ from health workers, $3(15 \%)$ from none. Regarding awareness on weight gain supplements $8(40 \%)$ regarding olive oil, $7(35 \%)$ regarding lipid emulsions, 5(25\%) regarding formula feeding. Regarding gestational age of the mother $2(10 \%)$ are $37-35$ weeks, $6(30 \%)$ are 35-33 weeks, 6(30\%) are 33-30 weeks, 3(60\%) are< 30 weeks. Regarding medical problems during antenatal period $7(35 \%)$ infection, $2(10 \%)$ having placental factors, $7(35 \%)$ multiple gestations, $4(20 \%)$ none. Regarding history of preterm delivery $10(50 \%)$ were preterm delivered, $10(20 \%)$ were not delivered. Regarding high risk problems $0(0 \%)$ are pre- eclampsia, $1(5 \%)$ placenta preavia, 9(45\%) PPH, 10(50\%) none. Regarding age of the infant 3(15\%) are 0-7 days, 5(25\%) are 8-14 days, $7(35 \%)$ are $15-21$ days,5(25\%) is $21-28$ days. Regarding gender $12(60 \%)$ are males, $8(40 \%)$ are females. Regarding birth weight of the infant $8(40 \%)$ are $<1000$ grms $10(50 \%)$ are 1000-1500gm, 2(10\%) are 2000-2500gm. Regarding immediate cry $14(70 \%)$ were immediately cried, 6(30\%) were absence of cry. Regarding Apgar score $8(40 \%)$ are $3-5,2(20 \%)$ are 5-7, 0(0\%) are 7-10, 7(35\%) are <6 Regarding presence of reflexes 7(35\%) are 6-10, $6(30 \%)$ are $10-12,0(0 \%)$ 12-14. Regarding birth order $10(50 \%)$ are 1 st child, $8(40 \%)$ are 2 nd child, $2(10 \%)$ are $3 r d$ child. Regarding medical problems of child 6(30\%) are metabolic disorder, $9(45 \%)$ are birth asphyxia, $0(0 \%)$ are meconium aspiration 5(25\%) are congenital anamolies. Regarding type of feeding 6(30\%) are direct breast feeding, $4(20 \%)$ are expressed breast feeding, 2(10\%) formula feeding, $4(20 \%)$ are NG tube feeding $4(20 \%)$ spoon feeding. Regarding kangaroo mother care 6(30\%) are every 2nd hourly, 9(45\%) every 4th hourly, 5(25\%)are 6th hourly. Regarding time of initiation of feed after birth 3(15\%) 1-2 hours, 8(40\%) 2-4 hours , 7(35\%) 4-6 hours ,2 (10\%) after 6 hours. Regarding total number of feeds per day. 8(40\%) every 2 nd hourly , $8(40 \%)$ every 4 th hourly, $4(20 \%)$ every 6th hourly

During pre test in experimental group 11 (55\%) were with 500-1000gm, weight in pre test, 9 (45\%) were with $1001-1500 \mathrm{gm}$ weight in pre test, and none of them were with 1501- 2000gm. In control group 10(55\%) were with 500-1000gm weight, 7(35\%) were with 1001-1500gm weight, 3(15\%) were with 1501-2000gm.

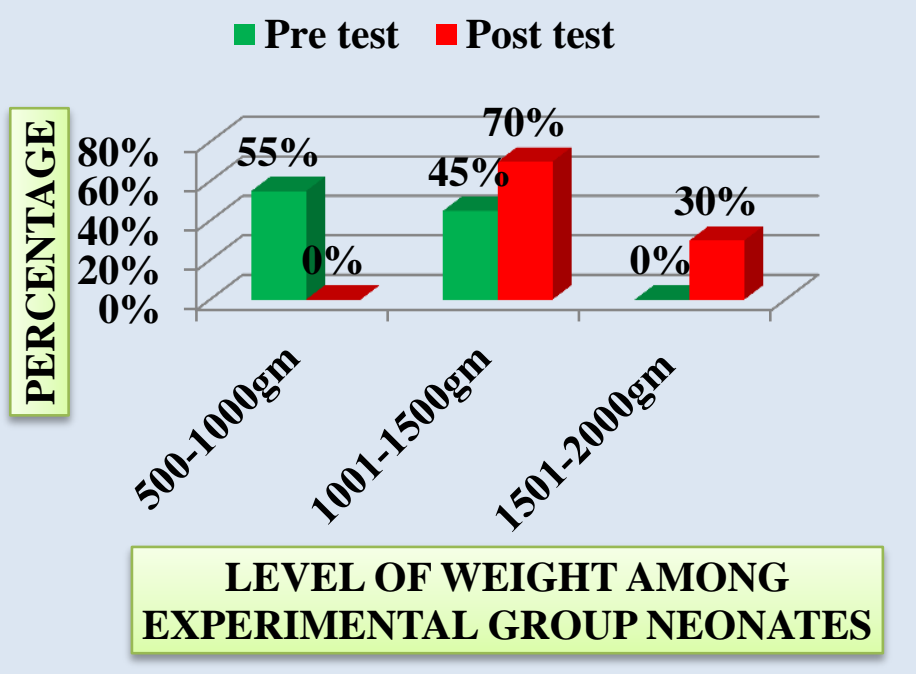

The pre test findings are 9(45\%) were with 1001-1500 and the post test values are found to be $14(70 \%)$ is the majority findings after intervention. During post test in experimental group found nil, for 500-1000gm, 14(70\%) were with 1001-1500gm weight, and 6(30\%) were with 1501-2000gm. In control group 8(40\%) were with 500$1000 \mathrm{gm}$ in post test, $8(40 \%)$ were with $1001-1500 \mathrm{gm}$, and 4(20\%) were with 1501-2000gm weight in post test, 


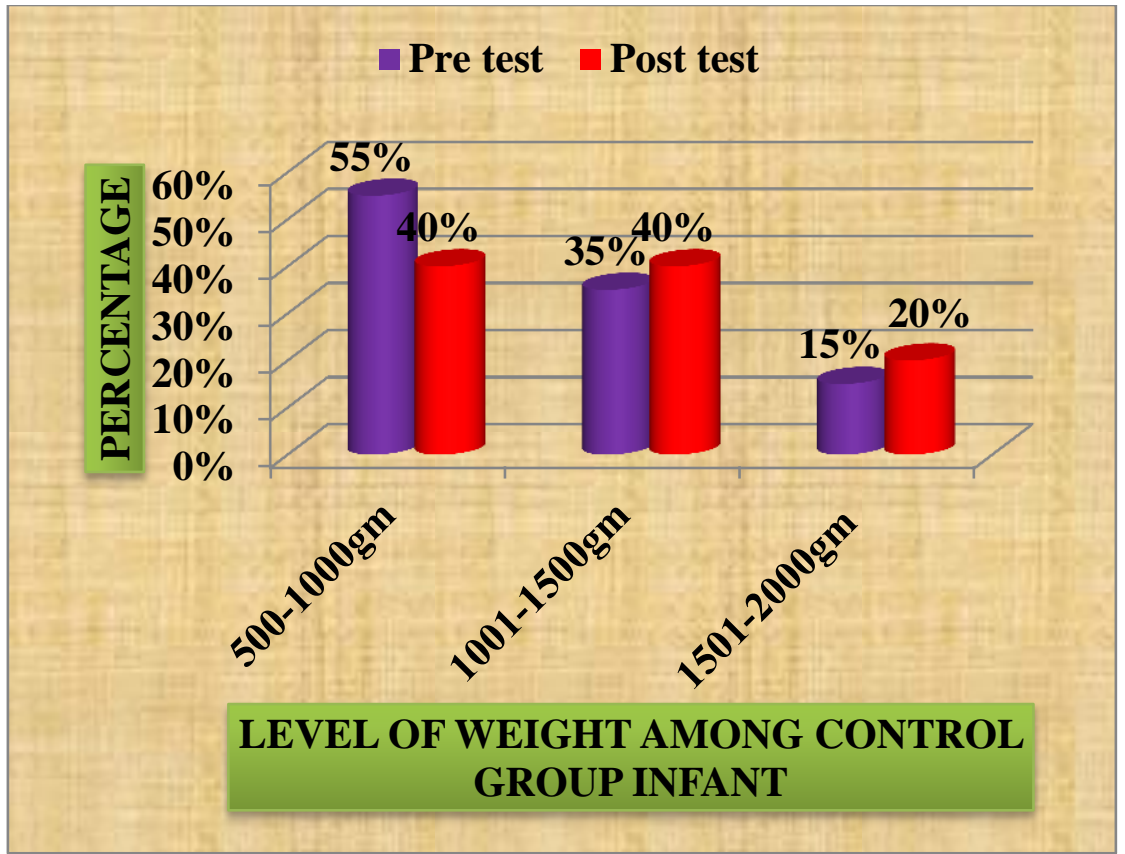

The mean score on level of weight gain in experimental group was 1415.25 in post test and 1104.85 in control group post test. The estimated paired ' $\mathrm{t}$ ' value was 3.88 which is significant at $p$ 0.001. It indicates that administration of olive oil through NG tube was effective in improving weight among low birth weight babies. Hence research hypothesis $\mathrm{H} 1$ was accepted.

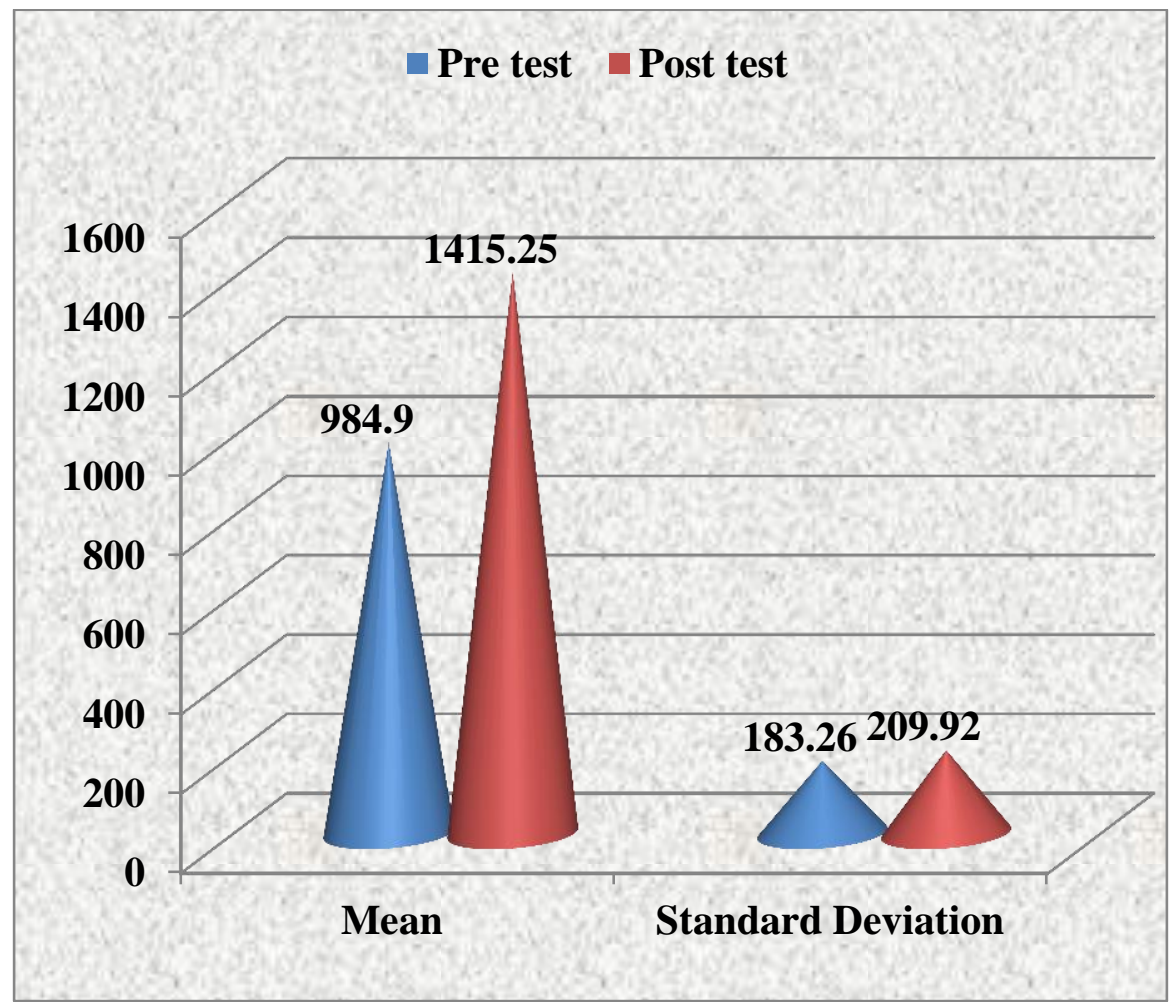




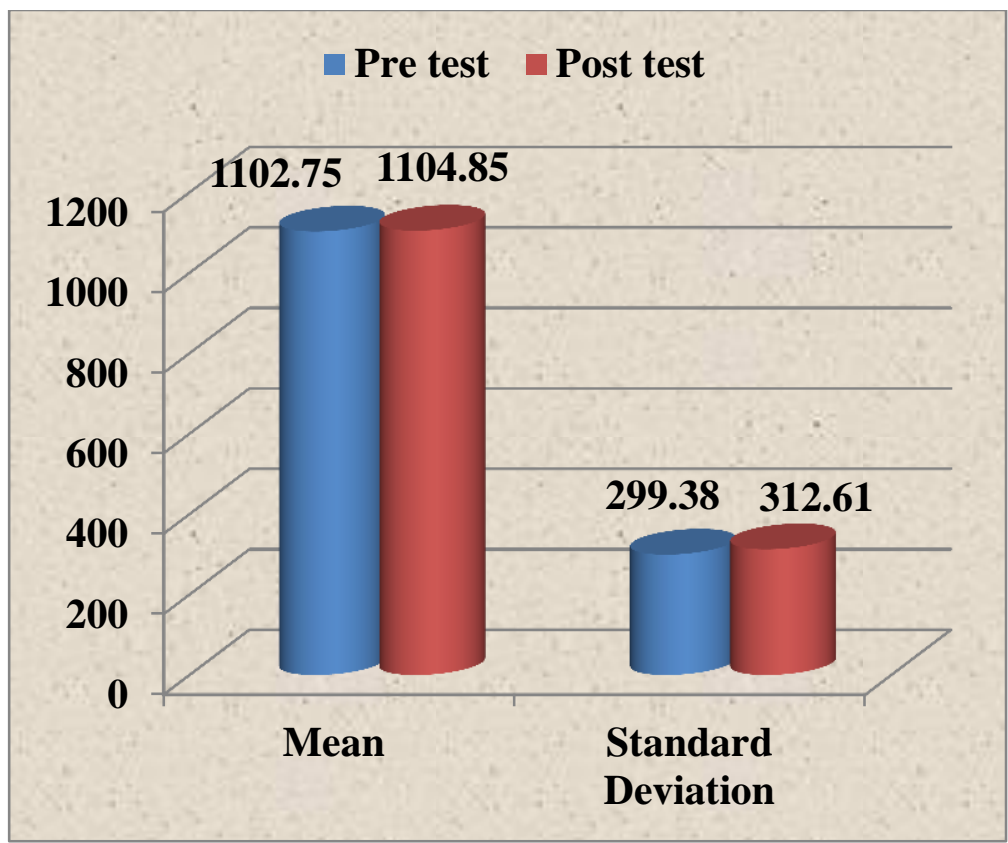

There was no significant association $(p<0.001)$ between the weight among low birth weight babies with their selected demographic variables between the experimental group and control group. Hence, hypothesis $\mathrm{H} 2 \mathrm{was}$ not accepted.

\section{RECOMMENDATIONS}

- A similar study can be conducted with large number of samples on antenatal mothers

- A study can be conducted with more than one month of intervention

- A descriptive study can be conducted on nursing students with VAP, STP, information booklet and Module

- A study can be conducted among low birth weight babies who are intubated and debilitated.

- This study can also be conducted as a comparative study using coconut oil, vegetable oil administration, administration of lipids, formula feeding, lipid emulsions etc.

\section{INTERPRETATION AND CONCLUSION}

The study has showed that there was an overall improvement in the weight among low birth weight babies after administration of olive oil through NG tube to improve weight among low birth weight babies admitted in NICU at SVS Hospital, yenugonda, Mahabubnagar, Telangana.

\section{REFERENCES:}

1. Parul Datta, "Text Book Of Pediatric Nursing" , $3^{\text {rd }}$ edition, Published by Jaypee Brothers, Page no:102-111

2. World Health Organization. Global nutrition targets 2025: low birth weight policy brief ,Geneva: World Health Organization; 2014.

3. Kumar M, Verma R, Khanna P, Bhalla K, Kumar R, Dhaka R, et al. Prevalence and associate factors of low birth weight in North Indian babies: a rural based study. Int J Community Med Public Health. 2017;4(9):3212-7.

4. State of India's Newborns (2004): New Delhi/Washington DC. NNF \& Save the Children/US, 2004: page no43-65.

5. Kramer MS. Intra Uterine Growth \& Gestational Duration Determinants. Paediatrics 1987;80(4):page no502- 11.

6. Dutta. Low Birth Weight Baby. In: Hiralal Konar, editor, Text Book of Obstetrics, 7th Edition, Kolkata: New Central Book Agency(P) Ltd; 2011: page no456-467.

7. Bhargava SK, Bhargava V, Kumari S, Madhavan S, Ghosh S. Birth weight, Gestational age \& Maternal Factors in Low Birth Weight babies. Indian Paediatrics 1973;page no10(3):161-6.

8. United Nations Children's Fund and World Health Organization, Low Birth weight: Country, regional and global estimates. UNICEF, New York, 2004. 
9. Gawecka A, Michalkiewicz J,JPEN J Parenteral Enteral Nutrition United Nations Children's Fund and World Health Organization, Low Birth regional and global estimates. UNICEF, New York, 2004.

10. Stoll BJ, chapman IA . the high risk infants in Behrman RE Jenson HB Text Book of Paediatrics Phildelphia WB saunders;page no:702-4

11. Chukwudi NK,et al Global Pediatric Health 2018.

12. Bharati P, Pal M, Bandyopadhyay M, Bhakta A, Chakraborty S, Bharati P. Prevalence and causes of Low birth weight in India. Malays J Nutr. 2011;17(3):page no301-13Paliwal A, Singh V, Mohan I, Choudhary RC, Sharma BN. Risk factors associated with low birth weight in newborns: a tertiary care hospital based study. IJCRR. 2013;5(11):page no42-8.

13. Yadav DK, Chaudhary U, Shrestha N. Risk Factors Associated with Low Birth Weight. JNHRC. 2011;9(2):page no159-64.

14. Dandekar RH, Shafee M, Sinha SP. Prevalence and Risk factors affecting low birth weight in a district hospital at Perambalur, Tamil Nadu. Global J Med Pub Health. 2014;3(2):page no1-5.

15. Manna N, Sarkar J, Baur B, Basu G, Bandyopadhyay L. Socio-Biological Determinants of Low Birth Weight: A Community based study from rural field practice area of Medical College, Kolkata, West Bengal. J Dent Med Sci. 2013;4(4):page no33-9.

16. Deshpande JD, Phalke DB, Bangal VB, Peeyuusha D, Bhatt S. Maternal risk factors for low birth weight neonates: a hospital based case-control study in rural area of western Maharashtra, India. National J Community Med. 2011;2(3):page no394-8.

17. Celik HT,Yigit S,Yenidogan ve premature Bebeklerde parenteral Beslenmede Yenilikler. Hacettepe Tip dergisi 2009; 40: page no 176-189. 